ARTICLE

\title{
A circumpolar dust conveyor in the glacial Southern Ocean
}

\author{
Torben Struve (i) ${ }^{1 凶}$, Katharina Pahnke (1) ${ }^{1}$, Frank Lamy (1) ${ }^{2}$, Marc Wengler ${ }^{2}$, Philipp Böning ${ }^{1}$ \& \\ Gisela Winckler (10 ${ }^{3,4}$
}

The increased flux of soluble iron (Fe) to the Fe-deficient Southern Ocean by atmospheric dust is considered to have stimulated the net primary production and carbon export, thus promoting atmospheric $\mathrm{CO}_{2}$ drawdown during glacial periods. Yet, little is known about the sources and transport pathways of Southern Hemisphere dust during the Last Glacial Maximum (LGM). Here we show that Central South America ( $\left.24-32^{\circ} \mathrm{S}\right)$ contributed up to $80 \%$ of the dust deposition in the South Pacific Subantarctic Zone via efficient circum-Antarctic dust transport during the LGM, whereas the Antarctic Zone was dominated by dust from Australia. This pattern is in contrast to the modern/Holocene pattern, when South Pacific dust fluxes are thought to be primarily supported by Australian sources. Our findings reveal that in the glacial Southern Ocean, Fe fertilization critically relies on the dynamic interaction of changes in dust-Fe sources in Central South America with the circumpolar westerly wind system.

\footnotetext{
${ }^{1}$ Marine Isotope Geochemistry, Institute for Chemistry and Biology of the Marine Environment (ICBM), University of Oldenburg, 26129 Oldenburg, Germany. ${ }^{2}$ Alfred Wegener Institute for Polar and Marine Research, 27568 Bremerhaven, Germany. ${ }^{3}$ Lamont-Doherty Earth Observatory of Columbia University, Palisades,

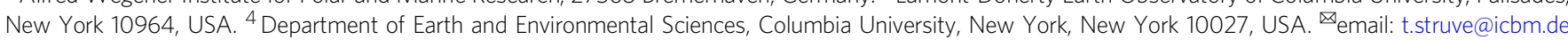


ir trapped in Antarctic ice indicates that glacial atmospheric $\mathrm{CO}_{2}$ concentrations were lower by about 80-100 p.p.m. compared to interglacial levels over the past 800,000 years ${ }^{1}$. Past variability in the atmospheric $\mathrm{CO}_{2}$ concentrations was synchronous with variations in air temperature and dust deposition over Antarctica on glacial-interglacial to millennial time scales ${ }^{1-3}$.

It has been hypothesized that physical and biogeochemical feedbacks in the Southern Hemisphere enhanced the net primary productivity and carbon export during glacials playing a crucial role for the observed coupling between dust, $\mathrm{CO}_{2}$, and temperature changes ${ }^{4-7}$. The deficiency of the micronutrient iron $(\mathrm{Fe})$ is considered a limiting factor for phytoplankton growth in the Southern Ocean ${ }^{8-10}$. Martin ${ }^{8}$ proposed that the increased input of Fe-bearing mineral dust to the Southern Ocean would lead to increased primary productivity and enhanced oceanic sequestration of $\mathrm{CO}_{2}$ during past glacial periods. This relationship has been studied extensively in the modern Southern Ocean ${ }^{9,10}$ where the export of organic carbon from the surface to the deep ocean can be particularly efficient ${ }^{11}$. However, the effects on net carbon export remain equivocal, partly due to the temporal and spatial limitations of artificial Fe fertilization experiments ${ }^{10,12}$. More continuous natural Fe fertilization in the Southern Ocean suggests higher carbon export, but spatial limitations remain ${ }^{10}$.

Evidence for large-scale natural Fe fertilization experiments is preserved in the marine geological record and confirms the mechanistic link between Southern Ocean dust deposition, primary productivity, $\mathrm{CO}_{2}$, and temperature during the late Pleistocene glacial-interglacial cycles $^{5-7}$. Specifically, the dust-Feinduced increases in primary productivity enhanced nutrient consumption and export productivity (i.e., export of organic carbon) in the Southern Ocean Subantarctic Zone (SAZ) during past glacials $5,6,13$. This effect was suggested to account for a net drawdown of atmospheric $\mathrm{CO}_{2}$ of up to $\sim 40$ p.p.m. representing almost half of the total glacial-interglacial change $e^{6,7,14}$.

The data-based estimates of dust-Fe-induced drawdown of atmospheric $\mathrm{CO}_{2}$ critically rely on reconstructions of particle fluxes and nutrient consumption from the South Atlantic and extrapolation of the results to the entire Southern Ocean ${ }^{5,6}$. These estimates do not take into account contributions from different dust sources in the Southern Hemisphere ${ }^{15,16}$. However, the solubility and bioavailability of dust-borne Fe in the surface ocean is controlled by the complex interaction of multiple factors, including source area particle mineralogy ${ }^{17-20}$, atmospheric transport (organic complexation, (photo)chemical reactions and $\mathrm{pH}$, and particle sorting $)^{18,21,22}$, sea-ice processing ${ }^{23,24}$, surface ocean photochemistry, and seawater biogeochemistry (Fe chemistry, biotic processing, abundance and type of organic ligands, and particle interactions) $)^{21,22,25}$. Changes in dust provenance are primarily linked with variations in source area mineralogy and the characteristics of atmospheric particle transport influencing particle-liquid interaction in the atmosphere and in the surface ocean $^{18,22}$.

In the present day, the largest contributions to the total dust flux in the individual sectors of the Southern Ocean are immediately upwind in Australia, South America, and South Africa following the circumpolar flow of the Southern Hemisphere Westerly Winds (SWW) 15,26,27 (Supplementary Fig. 1). Air parcel trajectories suggest that dust emissions from all continental dust sources in the mid-latitude Southern Hemisphere, including New Zealand, can contribute to the total dust flux to the Southern Ocean ${ }^{16}$. However, Australia and South America are typically considered the most prominent dust sources in the Southern Hemisphere, hosting multiple dust source regions in their (semi) arid continental interior and on the eastern side of the Andes, respectively ${ }^{26-29}$. The modern dust emissions from terrestrial source regions in the Southern Hemisphere have been traced downwind using their distinct geochemical fingerprints ${ }^{28,30-35}$.

Reconstructions of dust provenance in past environments benefit from the geochemical differences between individual potential dust source areas (PSAs) and revealed that southern South American sources, and in particular Patagonia (south of $38^{\circ} \mathrm{S}$ ), dominated the dust supply to East Antarctica during glacials $28,31,36-39$. Yet, currently available Antarctic ice-core data do not unambiguously resolve specific terrestrial sources due to geochemical similarities between important dust sources in Australia, New Zealand, and South America $31,33,37,40$, and/or analytical limitations resulting from the low abundance of lithogenic dust particles in Antarctic ice ${ }^{35,38}$. Previous work from the South Pacific SAZ showed that the general pattern of glacial-interglacial variability in dust deposition resembles the characteristics of Antarctic ice-core records, with higher input during glacials compared to interglacial periods ${ }^{41}$. The increased glacial dust supply to the South Pacific SAZ was ascribed to Australian and/or New Zealand sources synchronized with Patagonian dust emissions by large-scale common climate forcing $20,41,42$. However, relatively little is known about sources and transport of dust to the glacial South Pacific SAZ ${ }^{42}$ comprising the largest area for oceanic $\mathrm{CO}_{2}$ sequestration through $\mathrm{Fe}$ fertilization in the Southern Hemisphere. Hence, characterizing the sources of dust input to the South Pacific SAZ during the Last Glacial Maximum (LGM) is paramount to further understanding the role of the Southern Hemisphere dust cycle in the glacial drawdown of atmospheric $\mathrm{CO}_{2}$. Here we use a set of complementary, but independent geochemical tracers including rare earth elements (REEs), strontium ( $\mathrm{Sr}$ ), neodymium $(\mathrm{Nd})$, and lead $(\mathrm{Pb})$ isotopes to constrain sources and transport paths of dust delivered to the mid-latitude South Pacific during the LGM. Our data reveal remarkable changes in the geochemistry and spatial distribution of dust between the LGM and the Holocene, refining the existing picture of the glacial Southern Hemisphere dust cycle.

\section{Results and discussion}

Isotope signatures of South Pacific fine fraction sediments. For this study, we selected 18 locations between $\sim 2$ and $5 \mathrm{~km}$ water depth covering the mid-latitude South Pacific from $\sim 174^{\circ} \mathrm{E}$ to $\sim 75^{\circ} \mathrm{W}$ and from $\sim 45^{\circ} \mathrm{S}$ to $\sim 63^{\circ} \mathrm{S}$ across the Antarctic Circumpolar Current (ACC) (Fig. 1). For each location, we typically processed five samples of the $<5 \mu \mathrm{m}$ sediment fraction across the LGM interval between 18,000-24,000 years before present (i.e., $18-24 \mathrm{ka} \mathrm{BP})(n=85)$, which was identified using available age constraints (see Supplementary Data File 1).

We have chosen the $<5 \mu \mathrm{m}$ size fraction for our dust provenance study, because the long atmospheric lifetime of this size fraction ${ }^{43}$ enables inter-continental (long-range) airborne transport $^{44}$ and thus the dominant role of $<5 \mu \mathrm{m}$ particles in the lithogenic sediment fraction of the South Pacific $\mathrm{SAZ}^{45}$. Furthermore, moderate changes in grain-size composition during atmospheric transport ${ }^{43}$ reduce possible bias from grain-size effects in the $<5 \mu \mathrm{m}$ fraction, thus allowing direct comparison to many geochemical data sets from terrestrial PSAs. An additional asset is that the high cohesiveness of this size fraction minimizes resuspension and post-depositional transport by bottom currents ${ }^{46}$. The details of sample preparation and analyses are outlined in the "Methods" section. The results are reported as averages per sampling location with $2 \mathrm{SD}$ across the LGM time slice $(n=2-7)$.

We obtained $\mathrm{Nd}$ isotope compositions (expressed as $\varepsilon_{\mathrm{Nd}}$; see "Methods" for more details) between $\varepsilon_{\mathrm{Nd}}=-3.7 \pm 0.5$ and $-5.3 \pm$ 0.9 , and $\mathrm{Sr}$ isotope compositions ranging from ${ }^{87} \mathrm{Sr} /{ }^{86} \mathrm{Sr}=0.7083 \pm$ 


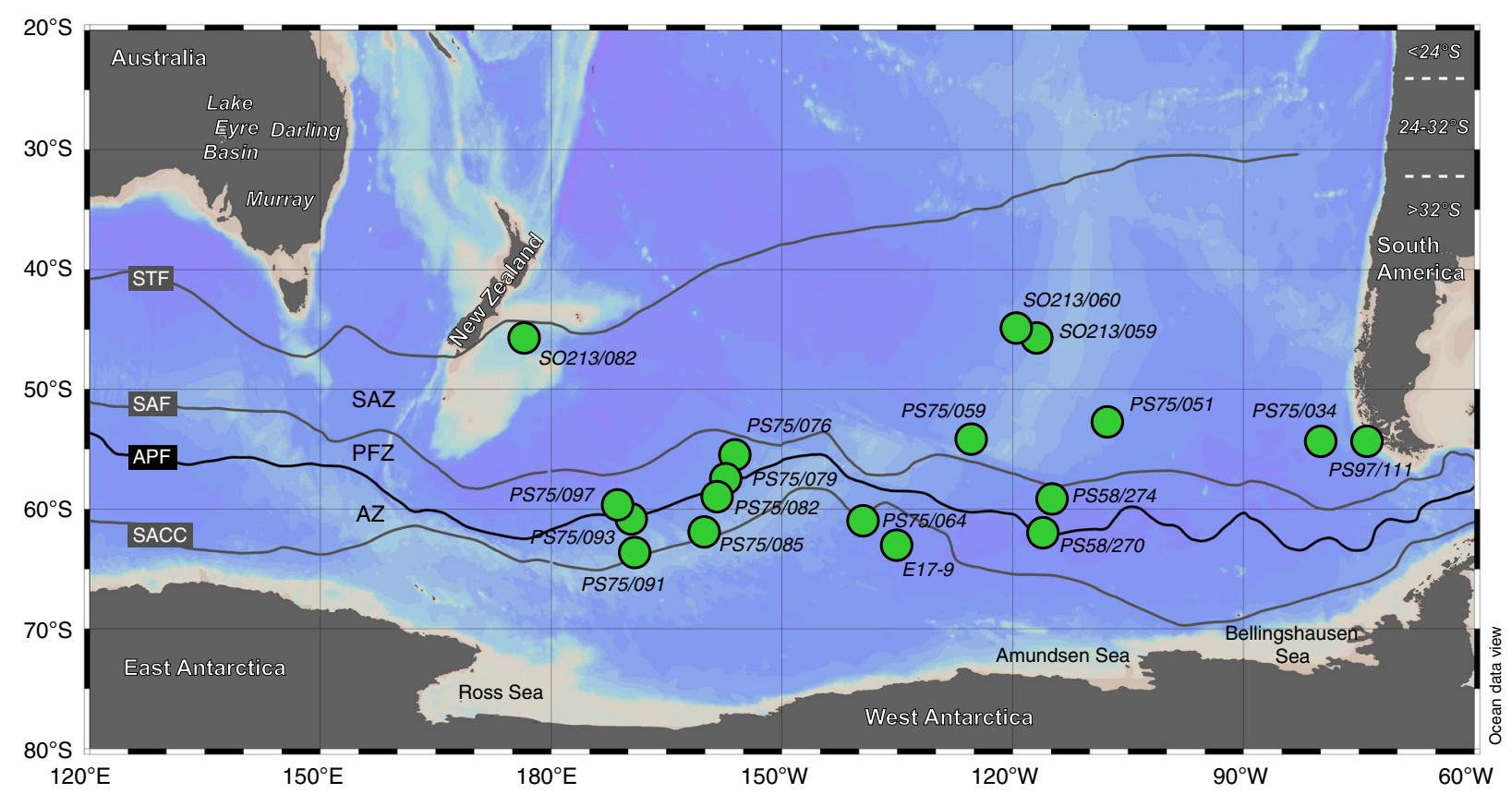

Fig. 1 Sample locations in the South Pacific. Main terrestrial potential source areas (PSAs) indicated with white labels. South American dust sources are grouped into latitudinal bands. In the text, PSAs between 24 and $32^{\circ} \mathrm{S}$ are also referred to as Central South America, whereas Southern South America describes the PSAs south of $32^{\circ} \mathrm{S}$. Southern Ocean fronts from ref. ${ }^{94}$. STF: Subtropical Front. SAF: Subantarctic Front. APF: Antarctic Polar Front. SACC: Southern ACC Front. SAZ: Subantarctic Zone. PFZ: Polar Frontal Zone. AZ: Antarctic Zone. Map created with Ocean Data View ${ }^{95}$.
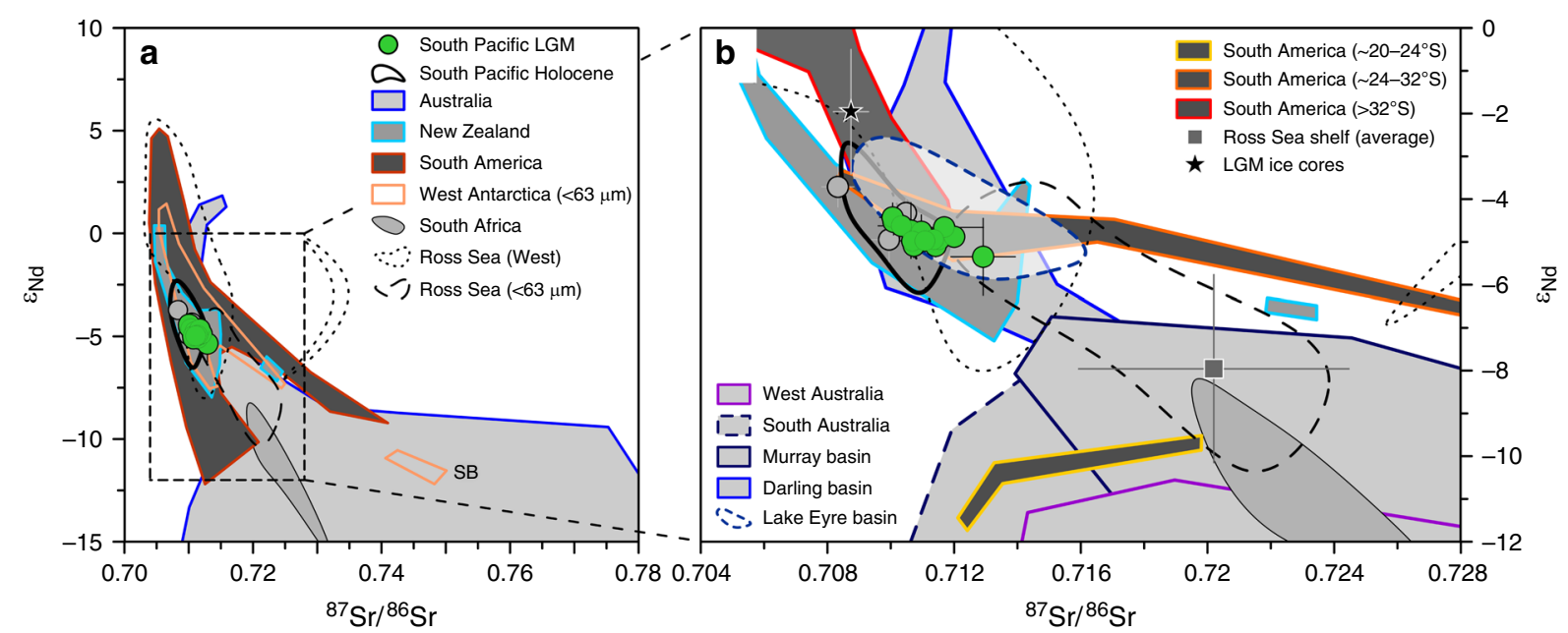

Fig. 2 South Pacific Last Glacial Maximum fine fraction samples in Nd-Sr isotope space. Remote open ocean samples in green and locations at/near the continental margins in gray. Last Glacial Maximum (LGM) data points and error bars represent averages and their 2 SD across the LGM interval ( $18-24$ ka BP). See Supplementary Fig. 1 and Supplementary Tables 2 and 3 for details and references to terrestrial source area data. a Overview of potential source area compositions in the Southern Hemisphere. West Antarctic and Ross Sea shelf data obtained from < $63 \mu \mathrm{m}$ fractions $\mathrm{s}^{50,96}$. SB: Sulzberger Bay. b Detailed view with South American and Australian source areas subdivided into individual provinces. Average values for Antarctic ice cores calculated from LGM age samples at Dome $B$ and $C\left(\varepsilon_{\mathrm{Nd}}=-2.0 \pm 1.5,{ }^{87} \mathrm{Sr} /{ }^{86} \mathrm{Sr}=0.7087 \pm 0.0006,2 \mathrm{SD}, n=9\right)^{31,44}$. Ross Sea shelf average ${ }^{96}$ is indicative of the composition of ice-rafted detritus exported into the South Pacific ${ }^{47}$. Note the isotopic difference of Southwest Pacific location PS75/091-3 relative to the remaining open ocean data (see Supplementary Note 5 and Supplementary Fig. 6 for further details).

0.0005 to $0.7129 \pm 0.0010$ (Fig. 2 and Supplementary Data File 2). The $\mathrm{Pb}$ isotope results for ${ }^{206} \mathrm{~Pb} /{ }^{204} \mathrm{~Pb}$ range from $18.831 \pm 0.027$ to $19.306 \pm 0.085$ with a tendency towards more radiogenic $\mathrm{Pb}$ isotope compositions and higher variability at locations in the South Pacific SAZ compared to the Antarctic Zone (AZ) (Fig. 3 and Supplementary Data File 2). Here we focus on the samples from the remote open ocean $(n=70)$. For more details on locations near the continental margins and PS75/034 close to South America, see Supplementary Note 3. All PSA data included in the discussion below were obtained from size fractions typical for far-traveled mineral dust $(<2,<5$, and $<10 \mu \mathrm{m})$ if not indicated otherwise (see Supplementary Fig. 1 and Supplementary Table 3 for more details).

Mode of fine particle transport to the glacial South Pacific. A prominent characteristic of our LGM $<5 \mu \mathrm{m}$ fraction data set is a relatively narrow range of $\mathrm{Nd}$ and $\mathrm{Sr}$ isotope compositions $\left(\varepsilon_{\mathrm{Nd}}\right.$ of $-4.9 \pm 0.6$ and ${ }^{87} \mathrm{Sr} /{ }^{86} \mathrm{Sr}=0.7111 \pm 0.0015, n=70,2 \mathrm{SD}$ of the remote open ocean sample population). This is in contrast to the 


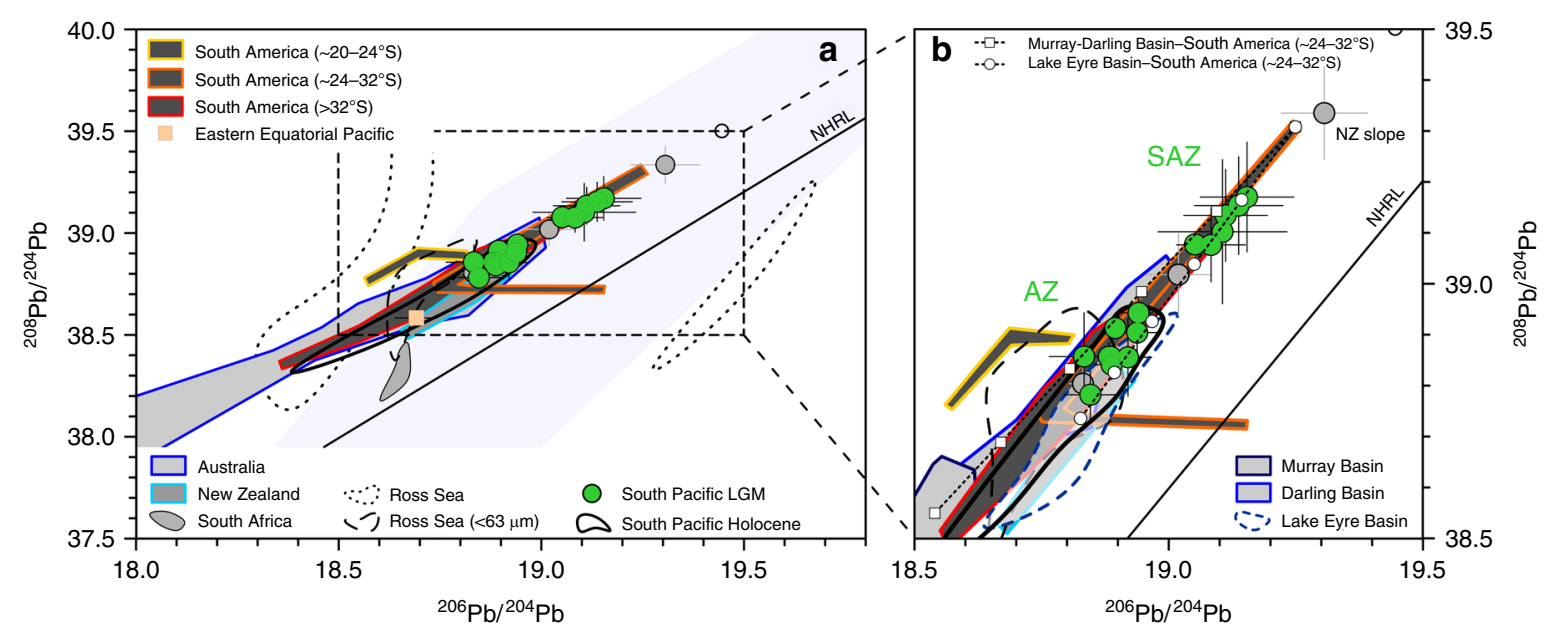

Fig. 3 South Pacific Last Glacial Maximum fine fraction samples in ${ }^{208} \mathbf{P b} /{ }^{204} \mathbf{P b}-{ }^{206} \mathbf{P b} /{ }^{204} \mathbf{P b}$ space. Remote open ocean samples in green and locations at/near the continental margins in gray. Last Glacial Maximum (LGM) data points and error bars represent averages and their 2 SD across the LGM interval ( $18-24$ ka BP). Black ring indicates coretop sample PS75/105-1 from the New Zealand shelf ${ }^{34}$. See Supplementary Fig. 1 and Supplementary Tables 2 and 3 for details and references to potential source area (PSA) data. a Overview of Southern Hemisphere PSA compositions. Average LGM value for the Eastern Equatorial Pacific from ref. ${ }^{71}$. Light blue shading indicates Dome C ice-core data ${ }^{38}$. NHRL: Northern Hemisphere Reference Line ${ }^{97}$. b Detailed view including endmember mixing models. Filled white symbols represent $20 \%$ increments of mixing of Central South America (24-32 ${ }^{\circ}$ ) with Lake Eyre (circles) and Murray-Darling endmembers (squares), respectively. Australia is subdivided into individual provinces. AZ: Antarctic Zone. SAZ: Subantarctic Zone. It is noteworthy that one Central South American sample is depleted in ${ }^{208} \mathrm{~Pb}$ relative to ${ }^{207} \mathrm{~Pb}$ (see Supplementary Fig. 4 for comparison), and that Lake Eyre Basin data were obtained from bulk sample material ${ }^{38}$.

large range of $\mathrm{Nd}-\mathrm{Sr}$ isotope compositions of Southern Hemisphere PSAs in Australia, New Zealand, South America, South Africa, and Antarctica (Fig. 2). Of these PSAs, Antarctica is the only source region which releases significant amounts of lithogenic material that can reach the mid-latitude South Pacific by multiple modes of transport including rafting ice, (re)suspension by bottom currents, turbidity flows, and dust ${ }^{24,34,42,47,48}$. Identifying lithogenic input from Antarctic sources is therefore pivotal to determine the mode of transport of fine fraction material to our sampling locations, in particular because our $\mathrm{Nd}$-Sr isotope data show overlap with the compositions of shelf sediments in the Pacific sector of Antarctica (Fig. 2).

Lithogenic material from Antarctica can reach the mid-latitude South Pacific via the main routes of ice rafting and bottom water export from the Ross Sea $24,42,47,49$. Sediment provenance tracers, which are less sensitive to grain-size effects, such as $\mathrm{Nd}$ and $\mathrm{Pb}$ isotopes $^{28,39,42}$ (see Supplementary Note 4), support Sr isotope evidence (see Supplementary Note 5) showing that the Ross Sea area was not a major source of $<5 \mu \mathrm{m}$ fraction sediment supply to our sample locations during the LGM (Figs. 3 and 4). Likewise, northwards penetrating turbidity flows are unable to supply significant amounts of lithogenic fine fraction material to the mid-latitude South Pacific ${ }^{34}$. Accordingly, the zonal diversity of NdSr isotope compositions of West Antarctic shelf sediments ${ }^{50}$ is not reflected in our LGM fine fraction data (Fig. 2). The confined icefree regions along East Antarctica's Ross Sea coast were shown to be a significant source of dust to the modern Southwest Ross Sea ${ }^{24}$ and at the nearby Taylor Glacier during the Holocene ${ }^{48}$. However, the dust signal from older ice of the Taylor Glacier was ascribed primarily to input from sources outside of the Antarctic continent $^{48}$. Taking into account that LGM dust fluxes were two orders of magnitude higher in the mid-latitude South Pacific $(\sim 120$ $\left.-200 \mathrm{mg} \mathrm{cm}^{-2} \mathrm{ka}^{-1}\right)^{41}$ than contemporaneous fluxes at the Taylor Glacier $\left(<\sim 1.2 \mathrm{mg} \mathrm{cm}^{-2} \mathrm{ka}^{-1}\right)^{48}$, we consider contributions from Antarctic dust sources to our study area insignificant.

Consequently, the lithogenic $<5 \mu \mathrm{m}$ sediment fraction was delivered to our South Pacific core locations primarily by airborne transport from terrestrial sources outside of the Antarctic continent, thus supporting previous suggestions that the lithogenic fluxes in the mid-latitude South Pacific reflect predominantly dust input ${ }^{41,42}$. Therefore, our $\mathrm{LGM}<5 \mu \mathrm{m}$ sediment fraction samples are also referred to as dust fraction.

Two main dust signatures in the glacial South Pacific. The key characteristic of our data set is a distinct latitudinal distribution of $\mathrm{Pb}$ isotope compositions of the dust fraction (Fig. 3). This pattern requires mixing of two dominating components including one component with radiogenic $\mathrm{Pb}$ isotope compositions and one with less radiogenic $\mathrm{Pb}$ isotope compositions dominating in the SAZ and AZ, respectively (Fig. 3b). Importantly, the relatively invariable $\mathrm{Nd}$ isotope signatures $\left(\varepsilon_{\mathrm{Nd}}\right.$ of $\left.-4.9 \pm 0.6,2 \mathrm{SD}, n=70\right)$ associated with the two different $\mathrm{Pb}$ isotope signals in our samples limit the possible PSA endmember compositions to a narrow range between $\varepsilon_{\mathrm{Nd}}$ of $\sim-4$ and $\sim-6$ (Fig. 4). This narrow $\mathrm{Nd}$ isotope range excludes a possible role for emissions from active volcanoes showing typically highly radiogenic $\varepsilon_{\mathrm{Nd}}$ of $\sim 6.5^{51}$. Moreover, the combined evidence from $\mathrm{Pb}, \mathrm{Nd}$, and $\mathrm{Sr}$ isotopes excludes South Africa as a significant dust source to our study area, consistent with existing model results ${ }^{15}$ (Figs. 2 and 3).

Australia hosts geochemically diverse source areas $29,32,40$ dominating the dust deposition in the mid-latitude South Pacific in the present day ${ }^{15,32,34}$. The Nd isotope compositions of PSAs in West $\left(\varepsilon_{\mathrm{Nd}}\right.$ of $\left.-17 \pm 8.3,2 \mathrm{SD}, n=21\right)$ and South Australia $\left(\varepsilon_{\mathrm{Nd}}\right.$ of $-12.2 \pm 6.1,2 \mathrm{SD}, n=38$ ) (Supplementary Table 2) 29,40 are inconsistent with the observed endmember $\varepsilon_{\mathrm{Nd}}$ range between $\sim$ -4 and $\sim-6$. The large Murray and Darling river basins in East Australia have been considered as important dust source regions during the last glacial period $29,52,53$. The $\mathrm{Pb}$ isotope compositions are variable and relatively unradiogenic in the two subbasins ${ }^{29,38,54}$ (Supplementary Table 2 and Fig. 3b), but systematic $\mathrm{Nd}$ isotope differences exist between the Murray $\left(\varepsilon_{\mathrm{Nd}}\right.$ of $-9.1 \pm$ $3.4,2 \mathrm{SD}, n=24)$ and the Darling Basin $\left(\varepsilon_{\mathrm{Nd}}\right.$ of $-2.6 \pm 4.2,2 \mathrm{SD}$, $n=19)^{29,55}$ (Supplementary Table 2 and Fig. 4). Consequently, an integrated signal contributing unradiogenic $\mathrm{Pb}$ from the 


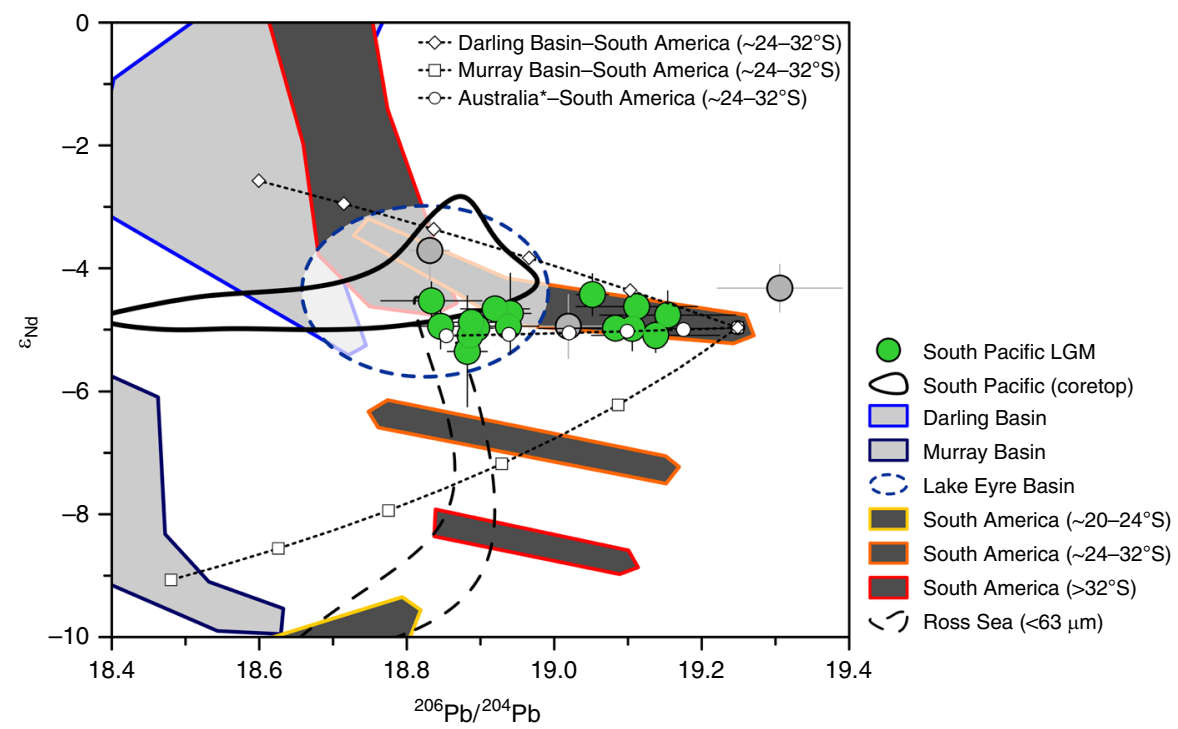

Fig. 4 South Pacific Last Glacial Maximum fine fraction samples in Pb-Nd isotope space. Last Glacial Maximum (LGM) data points and error bars represent averages and their 2 SD across the LGM interval ( 18-24 ka BP). The South Pacific coretop data include only open ocean locations; samples from the New Zealand and West Antarctic margins ${ }^{34}$, and sample PS75/084-1 are not included (see also Supplementary Note 6). The blue dashed circle approximates the Lake Eyre composition based on the data in Figs. 2 and 3 (see Supplementary Table 3 for references). Mixing between important source regions indicated by stippled lines, white symbols represent $20 \%$ increments. Australia* reflects the endmember composition as described in the main text. See Supplementary Table 2 for more details and Supplementary Table 3 for references to literature data. It is noteworthy that South Africa and New Zealand (overlap with Lake Eyre Basin) are not included here (see "Discussion" and Supplementary Note 2 and Supplementary Table 4).

Murray and Darling Basins could be explained by a $\sim 1: 1$ mixture of sources in the two basins to comply with $\varepsilon_{\mathrm{Nd}}$ values of $-4.9 \pm$ 0.6 in our LGM dust samples (Fig. 4). However, a 1:1 mixture would imply a large $\mathrm{Sr}$ isotope offset between the hypothetical endmember signal $\left({ }^{87} \mathrm{Sr} /{ }^{86} \mathrm{Sr}\right.$ of 0.7212 ) (Supplementary Table 2 ) and our South Pacific dust sample compositions $\left({ }^{87} \mathrm{Sr} /{ }^{86} \mathrm{Sr}\right.$ of $0.7111 \pm 0.0015)$. Notwithstanding that the Murray-Darling data were obtained from clay fraction sediments $(<2 \mu \mathrm{m})^{55}$ (Supplementary Table 3 ) showing typically elevated ${ }^{87} \mathrm{Sr} /{ }^{86} \mathrm{Sr}$ relative to larger grain $\operatorname{sizes}^{56}$ (see also Supplementary Note 4), the magnitude of this offset is difficult to reconcile with documented bias from grain-size effects in dust deposits $28,30,33,56$. Furthermore, it would be surprising if dust flux changes of up to approximately one order of magnitude ${ }^{52,53}$ yielded a relatively stable endmember mixing from geochemically distinct source regions in East Australia during the LGM.

Instead, we suggest that the Lake Eyre Basin in central Australia was the primary source of long-traveled dust carrying unradiogenic $\mathrm{Pb}$ to our core sites in the South Pacific during the LGM. A prominent role for this source region has been suggested previously based on $\mathrm{Nd}$ and $\mathrm{Sr}$ isotope compositions of bulk sediment samples from the central South Pacific ${ }^{42}$. Supporting evidence is provided by the remarkable resemblance of $\mathrm{Nd}$ and $\mathrm{Sr}$ isotope compositions in the Lake Eyre Basin $\left(\varepsilon_{\mathrm{Nd}}\right.$ of $-4.1 \pm 2.0$ and ${ }^{87} \mathrm{Sr} /{ }^{86} \mathrm{Sr}$ of $\left.0.7112 \pm 0.0038,2 \mathrm{SD}, n=17\right)^{29,40}$ with $<10 \mu \mathrm{m}$ fraction samples from the eastern Tasman Sea $\left(\varepsilon_{\mathrm{Nd}}\right.$ of $-5.1 \pm 1.4$ and ${ }^{87} \mathrm{Sr} /{ }^{86} \mathrm{Sr}$ of $0.7115 \pm 0.0012,2 \mathrm{SD}, n=2$ ) ${ }^{40}$ (Supplementary Table 2) and our LGM dust samples (Fig. 2). We emphasize that parts of the Darling Basin share geochemical characteristics with the Lake Eyre Basin, which could have contributed to the integrated signal of Australian dust emissions recorded at our core sites in the South Pacific (Figs. 2 and 4).

Similarity exists also between the $\mathrm{Nd}$ and $\mathrm{Sr}$ isotope compositions of our LGM dust samples $\left(\varepsilon_{\mathrm{Nd}}\right.$ of $-4.9 \pm 0.6$ and $\left.{ }^{87} \mathrm{Sr} /{ }^{86} \mathrm{Sr}=0.7111 \pm 0.0015\right)$ and $<5 \mu \mathrm{m}$ fraction sediments from New Zealand's South Island $\left(\varepsilon_{\mathrm{Nd}}\right.$ of $\sim-5.4 \pm 3.7,2 \mathrm{SD}, n=10$ and ${ }^{87} \mathrm{Sr} /{ }^{86} \mathrm{Sr}$ of $\left.0.7142 \pm 0.0103,2 \mathrm{SD}, n=10\right)^{31}$ (Supplementary Table 2) (Fig. 2b), which has been considered an important dust source during glacial periods ${ }^{16,20,41,42}$. Based on $\mathrm{Nd}, \mathrm{Sr}$, and $\mathrm{Pb}$ isotope compositions, it is not possible to unambiguously differentiate between the integrated Australian dust signal and New Zealand PSAs (Supplementary Table 2). Complementary REE data conflict with an important role of dust supply from New Zealand to our study area (Supplementary Note 2 and Supplementary Fig. 3). We note that the published dust fraction REE data from New Zealand are very limited and may not reflect the full range of New Zealand PSA REE compositions (Supplementary Fig. 3). Based on the currently available evidence, we use central Australian $\mathrm{Pb}^{38}$ and Tasman Sea $\mathrm{Nd}$ isotope data ${ }^{40}$ to constrain the composition of the dust endmember signal exported from Australia during the LGM (Supplementary Table 2). This central Australian source can explain up to $100 \%$ of the total dust deposition in the South Pacific AZ (Fig. 4).

The second component dominating in the South Pacific SAZ requires a dust source with radiogenic $\mathrm{Pb}$ isotope compositions of ${ }^{206} \mathrm{~Pb} /{ }^{204} \mathrm{~Pb}>19$, which are not characteristic for Australian PSAs $^{38,54}$ (Fig. 3b and Supplementary Table 2). The dust fraction of LGM sediments from the New Zealand margin yielded ${ }^{206} \mathrm{~Pb} /$ ${ }^{204} \mathrm{~Pb}$ of $19.31 \pm 0.09(2 \mathrm{SD}, n=5)$, which could represent a possible source of radiogenic $\mathrm{Pb}$ to the South Pacific SAZ (Fig. 3). However, these sediments are distinct from the PSA signatures on land and reflect a local signal limited to the New Zealand continental shelf and margin environment (see Supplementary Note 3), probably related to mineral sorting during riverine, coastal, and/or submarine sediment transport ${ }^{57}$. Terrestrial PSAs with sufficiently radiogenic $\mathrm{Pb}$ isotope compositions that could account for the second endmember in our $\mathrm{Pb}$ isotope array are rare in the Southern Hemisphere. South America is often considered the major source of long-traveled dust in the Southern Hemisphere during glacial periods $28,31,38,39$. Many South American PSAs, such as the Puna-Altiplano region between $\sim 20^{\circ}$ and $24^{\circ} \mathrm{S}$ and PSAs south of $\sim 32^{\circ}$ including Patagonia $\left(>38^{\circ} \mathrm{S}\right)$, show 
geochemical fingerprints that are inconsistent with the twocomponent mixing that is evident from our South Pacific dust fraction samples (Figs. 3 and 4).

From the main Southern Hemisphere PSA, only the area between $\sim 24^{\circ} \mathrm{S}$ and $32^{\circ} \mathrm{S}$ in Central South America hosts deposits with $\mathrm{Pb}$ and $\mathrm{Nd}$ isotope compositions that can account for the second endmember dominating the dust fraction in the South Pacific SAZ (Figs. 3 and 4, and Supplementary Fig. 4). The $\mathrm{Pb}$ and $\mathrm{Nd}$ isotope characteristics of two $<63 \mu \mathrm{m}$ fraction samples from $\sim 26^{\circ} \mathrm{S}\left({ }^{206} \mathrm{~Pb} /{ }^{204} \mathrm{~Pb}\right.$ of 19.15 and $\varepsilon_{\mathrm{Nd}}$ of $\left.\sim-7\right)$ and $\sim 28^{\circ} \mathrm{S}\left({ }^{206} \mathrm{~Pb} / 204 \mathrm{~Pb} \text { of } 19.25 \text { and } \varepsilon_{\mathrm{Nd}} \text { of } \sim-5\right)^{28,39}$ are consistent with the composition of (volcano-)sedimentary rock deposits in the area reflecting a mixed signal of mantle-derived material and older continental crust ${ }^{33,58,59}$. The possible endmember $\mathrm{Pb}$ and $\mathrm{Nd}$ isotope compositions $\left({ }^{206} \mathrm{~Pb} /{ }^{204} \mathrm{~Pb}\right.$ of 19.25 and $\varepsilon_{\mathrm{Nd}}$ of $\left.\sim-5\right)$ feature relatively radiogenic ${ }^{87} \mathrm{Sr} /{ }^{86} \mathrm{Sr}$ of 0.7169 in the $<5 \mu \mathrm{m}$ sediment fraction ${ }^{28}$ (Supplementary Table 2), which seems inconsistent with the composition of our South Pacific dust samples (Fig. 2b). However, this can be reconciled with changes in the PSA weathering regime and/or different proportions of clay minerals in dust deposits relative to their source soils (see Supplementary Note 4). We suggest that the entrainment, long-range transport and/or deposition of dust discriminated against clay minerals with typically radiogenic $\mathrm{Sr}$ isotope compositions (high ${ }^{87} \mathrm{Sr} /{ }^{86} \mathrm{Sr}$ ) ${ }^{33,56}$, thus inducing a bias towards lower ${ }^{87} \mathrm{Sr} /{ }^{86} \mathrm{Sr}$ at the site of deposition. For example, particle size distributions of Central South American dust trap and source soil samples indicate a depletion of clay-sized particles in airborne dust relative to the source soils ${ }^{60}$. Such depletion may be related to the emission of clay minerals in aggregates and their preferential removal during transport relative to smaller, fully dispersed clay minerals ${ }^{43,61}$. Supporting evidence for this hypothesis is provided by the low abundance or absence of the clay minerals smectite and kaolinite in East Antarctic ice cores $^{44,62}$, which are important components of soils in the PSAs of South America and Australia ${ }^{63,64}$.

Using the most radiogenic $\mathrm{Pb}$ isotope signatures from Central South America (Supplementary Table 2), mixing calculations reveal that Central South America contributed up to $\sim 80 \%$ to the glacial dust deposition in the South Pacific SAZ, whereas the South Pacific AZ received up to $100 \%$ of dust from central Australia (Figs. 3b and 4). This finding is surprising, because Patagonia (south of $38^{\circ} \mathrm{S}$ ) is typically considered the major source of far-traveled dust coming from South America $6,31,37,38$, although Central South America has been invoked as an important dust source to the South Atlantic and East Antarctica $28,33,39$. The pattern is also fundamentally different to the modern situation that is characterized by Australian dust dominating in the entire study area ${ }^{15,34}$ and provides specific information about entrainment, transport, and deposition of airborne mineral dust during the LGM.

Glacial dust entrainment and circumpolar transport. We show that dust in the LGM South Pacific AZ was primarily derived from Australia. High emissions from central Australian dust sources are consistent with previous work on modern and past environments ${ }^{29,35,40,52,53,65,66}$. The combination of river systems supplying sediments to extensive alluvial plains and ephemeral lake plays could support efficient deflation of fine material in the expanded (semi)arid zone of central Australia during the LGM $^{29,53}$. Australian dust activity typically follows a seasonal cycle peaking during the spring and summer seasons, as a result of the complex interaction of migrating atmospheric pressure systems with sediment availability and erosivity in the dust source areas $^{26,27,29,53}$. In analogy to the modern situation, the distribution of mineral dust from Australia across the Tasman Sea $^{32,40}$ and the South Pacific was orchestrated by the eastward moving frontal systems of the SWW belt during the LGM.

The situation in the South Pacific SAZ is different. The prominent role of Central South America as a major dust source to the South Pacific SAZ during the LGM has not previously been shown. Modern observations and model simulations show pronounced dust activity in Central South American PSAs near $\sim 30^{\circ} \mathrm{S}^{27,60,67}$. Importantly, Central South American PSAs feature a number of environmental preconditions for the efficient production of fine particles including high relief, (semi)arid conditions with intermittent fluvial activity $26,27,33,67,68$, and increased glacier activity during glacial intervals ${ }^{69,70}$.

One mechanism to transport dust from South America to the South Pacific is westward by the trade winds. However, our study area is south of the low-latitude trade wind system today (Supplementary Fig. 1) and the $\mathrm{Pb}$ isotope composition of dust transported by the (sub)tropical Pacific trade winds during the LGM $\left({ }^{206} \mathrm{~Pb} /{ }^{204} \mathrm{~Pb}\right.$ of $18.69 \pm 0.05,2 \mathrm{SD}, \quad n=7$ including replicates $)^{71}$ is inconsistent with the dust signal recorded in the South Pacific SAZ $\left({ }^{206} \mathrm{~Pb} /{ }^{204} \mathrm{~Pb}\right.$ of $\left.19.09 \pm 0.17,2 \mathrm{SD}, n=28\right)$ (Fig. 3). Therefore, the only viable route of Central South American dust to the South Pacific SAZ was eastward on a circum-Antarctic path within the mid-latitude SWW belt (Supplementary Figs. 1 and 9).

Here we propose that increased SWW activity in Central South America north of $\sim 30^{\circ} \mathrm{S}$ facilitated efficient dust entrainment during the LGM, in particular during the winter season when the SWW regime reaches its northernmost extension ${ }^{68,72}$. In the present day, the mid-latitude SWW regime intersecting South America spans the lower troposphere westerly winds and the high-altitude jet streams ${ }^{33,72-74}$. The westerly winds are typically associated with strong dry foehn-like winds promoting dust entrainment on the eastern side of the Andes $28,30,33,39,60,67,75$. The high-altitude westerly jet circulation features a mid-latitude jet stream in the Southern Hemisphere, which is characterized by a weakened subpolar $\left(\sim 60^{\circ} S\right)$ and a strengthened subtropical branch $\left(\sim 30^{\circ} \mathrm{S}\right)$ over the South Pacific during austral winter ${ }^{73}$ (Fig. 5a). Modern observations, trajectory modeling, and geochemical evidence show that the subtropical jet stream plays an important role in the export and long-range transport of dust from high-altitude PSAs in Central South America ${ }^{33,60}$ (Supplementary Fig. 9). Recent work suggested that the subtropical jet stream was instrumental to enhance fluvial input at the Chilean continental slope near $27.5^{\circ} \mathrm{S}$ off the southern Atacama Desert during past glacials ${ }^{68}$.

We therefore conclude that SWW-induced orographic winds and intensified subtropical jet stream circulation $28,33,39,60,68,72$, possibly augmented by enhanced availability of fine material from glacier and (ephemeral) fluvial activity ${ }^{33,68-70}$, enabled efficient dust entrainment in and export from Central South American PSAs during the LGM. This scenario is consistent with the provenance of Argentinean loess and dust samples collected downwind of our suggested source region $28,30,39,60,75$, and with independent provenance constraints derived from heliumthorium isotope compositions of sediments in the South Atlantic ${ }^{76}$. The long-distance circumpolar transport of dust (Supplementary Fig. 9) was likely promoted by reduced wet deposition and increased lifetime of atmospheric dust during the $\mathrm{LGM}^{15}$. The increased abundance and prolonged residence time of $<5 \mu \mathrm{m}$ particles from Central South America would have enhanced scattering of incoming solar radiation, thus contributing directly to glacial cooling ${ }^{43}$. Different from the modern situation $^{34}$ and LGM model simulations ${ }^{15}$, these boundary conditions allowed Central South American dust to outpace the deposition from Australian sources in the South Pacific SAZ 

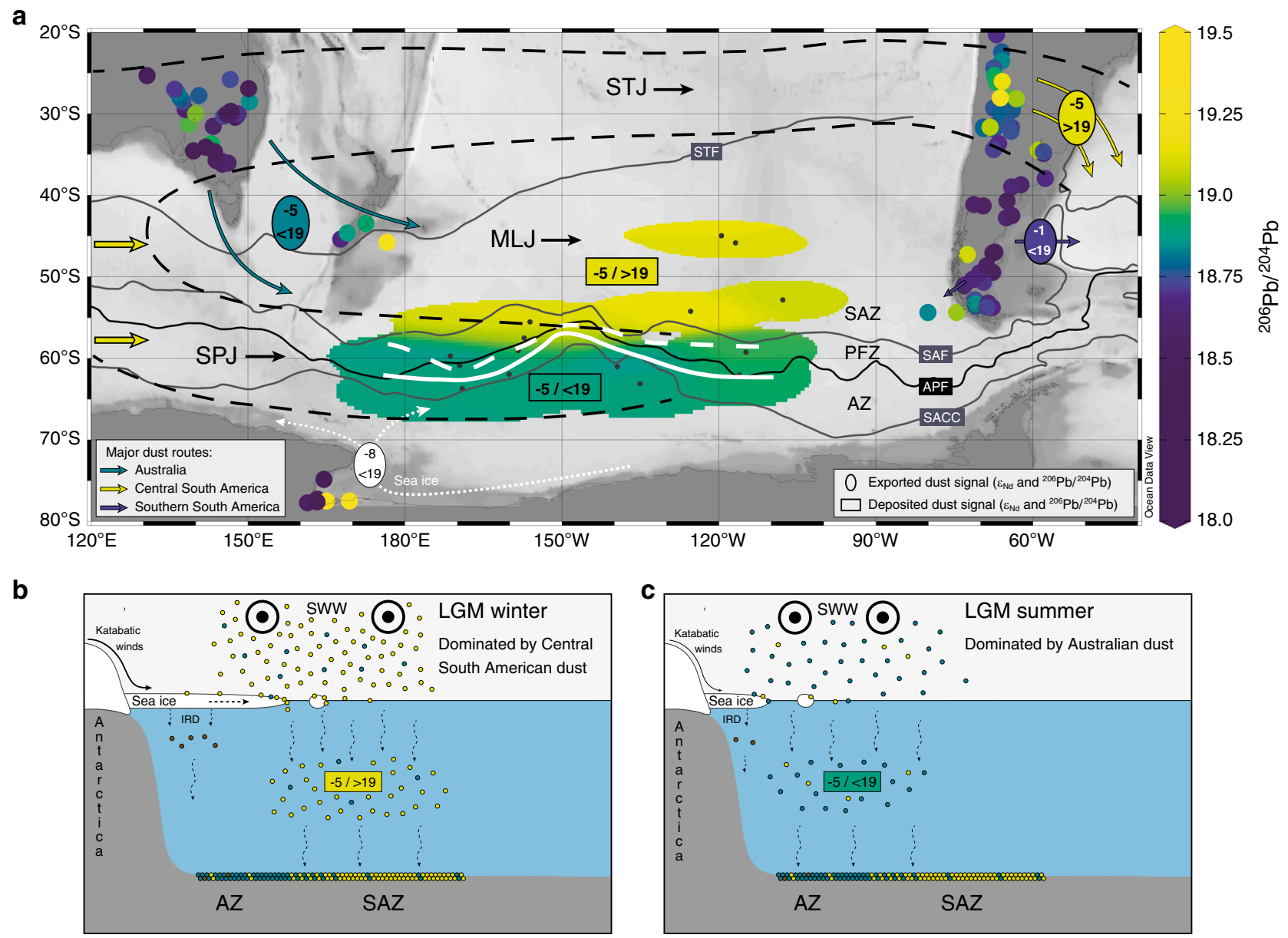

Fig. 5 The transport and deposition of dust in the South Pacific during the Last Glacial Maximum. a The distribution of dust fraction ${ }^{206} \mathrm{~Pb} /{ }^{204} \mathrm{~Pb}$ in the glacial South Pacific. Solid and dashed white lines delineate the limits of $40 \%$ and $15 \%$ winter sea-ice cover during the Last Glacial Maximum (LGM) ${ }^{77}$, respectively. Black dots: LGM time slice sampling locations. The dashed black outline indicates the modern zones of increased wintertime wind speed maxima in the high-altitude ( $200 \mathrm{hPa}$ ) westerly wind flow of the subtropical (STJ) and subpolar (SPJ) branches of the jet stream located north and south of the reduced mid-latitude jet $(M L J)$, respectively ${ }^{73}$. Terrestrial source data from the literature listed in Supplementary Table 3. It is noteworthy that some original terrestrial sample coordinates were slightly modified to improve visibility in this figure. Ocean fronts from ref. ${ }^{94}$. STF: Subtropical Front. SAF: Subantarctic Front. APF: Antarctic Polar Front. SACC: Southern ACC Front. SAZ: Subantarctic Zone. PFZ: Polar Frontal Zone. AZ: Antarctic Zone. Map created with Ocean Data View software ${ }^{95}$. b The LGM wintertime scenario. The northward expanded Southern Hemisphere westerly wind (SWW) system (STJ present in the South Pacific as in a) delivers dust efficiently on a circumpolar trajectory from Central South America to the study area. The extensive sea-ice cover reduces the dust deposition in the South Pacific AZ. IRD: ice-rafted detritus. Numbers in yellow box as in a. c The LGM summertime scenario. The STJ transporting dust from Central South America is absent, the SWW move closer to Antarctica and deliver predominantly Australian dust to the South Pacific AZ and SAZ north of the summer sea-ice limit. Numbers in green box as in $\mathbf{a}$. A comprehensive overview of tracer evidence constraining our proposed LGM scenario of circumpolar dust transport and deposition in the study area is provided in Supplementary Table 4.

during the LGM (Fig. 5a and Supplementary Table 4). The interplay of these two important terrestrial PSAs may explain the increased $\mathrm{Pb}$ isotope variability in particular in the South Pacific SAZ during the LGM interval (Fig. 3) and could have been involved in the geochemical variability of dust samples from Antarctic ice cores $28,31,33,38,39,44,48$.

Dust deposition in the glacial South Pacific. The two distinct dust depositional environments in the LGM South Pacific are characterized by a narrow transition zone (Fig. 5a), a pattern that cannot be controlled by variable atmospheric dust transport alone. Therefore, we invoke local oceanic processes modulating the settling of atmospheric dust fallout to the seafloor. The delineation between the two dust depositional zones shows remarkable correspondence with the position of the modern polar front and the LGM winter sea-ice $\operatorname{cover}^{77}$ (Fig. 5a). A primary control by hydrodynamic processes seems unlikely given the lacking correspondence between dust fraction geochemistry and the ACC fronts in the present day ${ }^{34}$. A characteristic feature of Southern Ocean sea-ice cover is a pronounced seasonal cycle ${ }^{77}$ such that the dust deposition at locations under the LGM winter sea-ice cover was reduced when dust transport from Central South American PSAs was presumably most efficient due to the enhanced northward expansion of the SWW/jet stream regime during the LGM winter season (see above). The offshore motion of wind and sea ice 24,49 would move the wintertime South American dust fallout out of the ice-covered ocean areas of the South Pacific AZ (Fig. 5a, b). A sea-ice control on the deposition of lithogenic particles is also evident from modern sediment trap data showing reduced lithogenic fluxes in the South Pacific AZ and increased fluxes in the $S A Z^{78,79}$. However, it may be speculated if additional processes were involved in the concentration of wintertime dust in the South Pacific SAZ during the LGM. For 
example, settling of particles is typically enhanced by aggregation 80,81 explaining also the close correspondence of biogenic and lithogenic particle fluxes in the Southern Ocean ${ }^{79}$. Dust particles released from sea ice to the AZ surface ocean during the melting season ${ }^{23,24}$ would be subject to further north (east)ward dispersal by the surface currents ${ }^{49}$. The earlier resumption of the primary productivity in the ice-free SAZ in spring ${ }^{78,79}$ could enhance the transfer of wintertime dust to the seafloor. During the rest of the year, the SWW/jet stream regime would not provide an efficient dust conveyor from Central South America to the South Pacific. Then, Australian dust fallout could dominate over the entire study area, including the region that is seasonally ice-free, but without outpacing the (winter) input from Central South America in the South Pacific SAZ (Fig. 5c).

As a result, the South Pacific SAZ was dominated by highly seasonal dust input from Central South American sources accounting for $\sim 50-80 \%$ of the total deposition and hence, for large parts of the threefold increase in glacial South Pacific SAZ dust fluxes ${ }^{41}$. We suggest that the seasonality of atmospheric dust supply from Central South America and sea-ice cover played important roles in modulating particle settling in the glacial South Pacific, thus inducing the distinct north-south trend in dust provenance evident from our data set (Fig. 5).

Dust provenance changes and Southern Ocean Fe supply. Previous estimates of a dust-induced $\sim 40$ p.p.m. lowering of glacial atmospheric $\mathrm{CO}_{2}$ concentrations critically rely on reconstructions from the South Atlantic SAZ, extrapolation of the results to the entire Southern Ocean, and a uniform value of $2 \%$ Fe solubility from mineral dust fallout ${ }^{5,6}$. However, the distinct pattern of LGM South Pacific dust provenance implies a change in source area particle mineralogy and in dust transport conditions, both of which can directly affect dust-Fe solubility $17,18,20,21$ with possible cascading effects on biogeochemical reactions in the atmosphere and in seawater ${ }^{18,22,25}$. Recent laboratory experiments with natural dust samples showed a close relationship between diatom growth and the content of more soluble Fe(II)rich silicate minerals typical for glaciogenic dust sources ${ }^{19}$. Reconstructions estimate a relatively uniform $\sim 15$-fold increase of $\mathrm{Fe}$ (II) supply to the glacial Southern Ocean in comparison to interglacial periods ${ }^{20}$. The similar phasing and magnitude of the glacial Fe(II) increase in the South Pacific and South Atlantic was related to the synchronized activity of chemically pristine (low degree of chemical weathering) glaciogenic mineral dust emissions from New Zealand and Patagonia, respectively ${ }^{20}$. Nonglaciogenic Australian PSA sediments show variable degrees of chemical maturity ${ }^{64}$, but dust from these sources might host less soluble Fe than chemically more pristine dust ${ }^{17,21}$. The contribution of Australian dust to the South Pacific could reduce the efficiency of a dust-induced glacial drawdown of atmospheric $\mathrm{CO}_{2}$ to less than the proposed $\sim 40$ p.p.m. Yet, our new data set suggests that the increased supply of primary Fe(II) silicates to the South Pacific SAZ ${ }^{20}$ was largely driven by mineral dust from chemically more pristine sources in (semi)arid Central South America $28,39,59,82$ (Figs. 4 and 5a). The solubility of dust-borne Fe from Central South America was probably further increased during the long circum-Antarctic transport ${ }^{22}$ and by (winter) seaice processing in the study area ${ }^{23}$. A possible reduction of $\mathrm{Fe}$ (II) supply by the contribution of more mature Australian mineral dust is then rendered negligible by the large-scale deposition and sea-ice processing of long-traveled Central South American dust. As such, our data can explain the zonally symmetric increase in $\mathrm{Fe}(\mathrm{II})$ supply to the Southern Ocean SAZ ${ }^{20}$, which stimulated primary productivity ${ }^{19}$, nutrient consumption ${ }^{6,13}$, and export production $^{5}$, thus supporting the increased sequestration of carbon in the glacial deep ocean ${ }^{4,14}$.

As a corollary, dust-borne Fe input as a critical component of the glacial-interglacial Fe feedback in the Southern Ocean was characterized by the interaction of the SWW system with changes in specific Central South American PSAs. This implies that Southern Ocean dust-Fe fertilization is highly sensitive to the environmental conditions in this important dust source region. Our findings are consistent with recent reconstructions of $\mathrm{Fe}$ supply to the subpolar Southern Ocean, but revise previous hypotheses of the source of the dust-borne Fe supply,6,20,41,42. It may be speculated whether the enhanced dust emissions from these Central South American PSAs were systematic and linear during the past glacial-interglacial cycles or if there was threshold behavior. The precessional forcing of the South Pacific subtropical jet stream dynamics ${ }^{68}$ would suggest that the LGM may not reflect whole glacial averages. Rather, our proposed link between dust activity in the source regions, the variable SWW system and the input of dust-borne Fe to the South Pacific SAZ indicates that the Southern Hemisphere dust-Fe supply can operate as a dynamic feedback on multiple time scales.

\section{Methods}

Grain-size separation and sediment leaching. For this study, we sampled about three cubic centimeters of wet bulk sediment for wet-sieving and subsequent Stokes-based separation of the $<5 \mu \mathrm{m}$ grain-size fraction in glass settling tubes at the Alfred Wegener Institute Bremerhaven. The $<5 \mu \mathrm{m}$ fraction was then subjected to a sequential leaching procedure at the Institute for Chemistry and Biology of the Marine Environment (ICBM) in Oldenburg to extract the lithogenic silicate frac$\operatorname{tion}^{34}$ (see also Supplementary Note 1 for more details). The $<5 \mu \mathrm{m}$ fraction samples were processed in a total of eight batches. One batch contained typically twelve samples, two procedural blanks, and the two United States Geological Survey (USGS) rock reference materials AGV-1 and BCR-2. All chemical and analytical sample processing was carried out at the ICBM using high-purity reagents ${ }^{34}$ if not indicated otherwise.

An aqueous solution with $\sim 5 \% \mathrm{H}_{2} \mathrm{O}_{2}$ was used to eliminate organics, followed by a two-step $1 \mathrm{M} \mathrm{HCl}$ leach ( $3 \mathrm{~h}$ and overnight) to remove carbonates and ferromanganese (oxy-)hydroxides. During a final step, the samples were exposed to 0.03 M EDTA ( $99.995 \%$ trace metals basis, Sigma-Aldrich ${ }^{\oplus}$ ) to sequester any remaining free and loosely adsorbed metal ions. After all steps the supernatant reagent was removed and the samples were triple-rinsed with Milli- $\mathrm{Q}^{\oplus} \mathrm{H}_{2} \mathrm{O}$. Then, the samples were freeze-dried and $\sim 50-100 \mathrm{mg}$ (depending on opal content) of freeze-dried sample material was weighed into ultra-clean polytetrafluoroethylene (PTFE) vessels fitting the PicoTrace DAS 30 pressure digestion system. To break down any remaining organic compounds, the samples were exposed to aqua regia at $130^{\circ} \mathrm{C}$ overnight, followed by pressure digestion at a nominal temperature of $230^{\circ} \mathrm{C}\left(180^{\circ} \mathrm{C}\right.$ measured in the digestion unit) using a mixture of concentrated $\mathrm{HF}-\mathrm{HNO}_{3}-\mathrm{HClO}_{4}$. After complete digestion, the samples were converted to chloride form, redissolved in $6 \mathrm{M} \mathrm{HCl}$, and split for REE analyses (see Supplementary Methods) and sequential wet-chemical extraction of target elements from the sample matrix following previously published procedures ${ }^{34}$. In brief, the sample aliquot was converted to bromide form for $\mathrm{HBr}-\mathrm{HNO}_{3}$-based $\mathrm{Pb}$ extraction using Biorad ${ }^{\oplus}$ AG1-X8 resin $^{83}$. The matrix wash fraction was collected to separate the alkaline earth metals from the REE using Biorad ${ }^{\circledast}$ AG50W X-8 resin ${ }^{84}$. Strontium was extracted from the remaining sample matrix using Eichrom Sr resin ${ }^{85}$ and Nd was isolated from the LREE with TrisKem Ln resin-based chemistry ${ }^{86}$.

Radiogenic isotope analyses. The $\mathrm{Pb}, \mathrm{Nd}$, and $\mathrm{Sr}$ isotope compositions were determined using a Thermo Scientific ${ }^{\mathrm{TM}}$ Neptune Plus ${ }^{\mathrm{TM}}$ multi-collector ICP-MS at the ICBM in Oldenburg. All reported AGV-1 and BCR-2 reference material results were obtained on leached residues (see above). For $\mathrm{Nd}$ isotope analyses, mass bias was corrected for using ${ }^{146} \mathrm{Nd} /{ }^{144} \mathrm{Nd}=0.7219$ and an exponential law. Isobaric interferences of ${ }^{142} \mathrm{Ce}$ and ${ }^{144} \mathrm{Sm}$ on ${ }^{142} \mathrm{Nd}$ and ${ }^{144} \mathrm{Nd}$ were monitored and corrected for using ${ }^{140} \mathrm{Ce}$ and ${ }^{147} \mathrm{Sm}$, respectively. The JNdi-1 reference material was measured every four samples to correct for the instrumental offset of the mass bias corrected ${ }^{143} \mathrm{Nd} /{ }^{144} \mathrm{Nd}$ ratios of the samples to JNdi-1 reference ratio of $0.512115 \pm 0.000007^{87}$. The external reproducibility of normalized ${ }^{143} \mathrm{Nd} /{ }^{144} \mathrm{Nd}$ ratios of acid-leached BCR-2 and AGV-1 rock powders was $0.512641 \pm 0.000013$ (2 SD, $n=29$ ) and $0.512794 \pm 0.000020$ ( $2 \mathrm{SD}, n=32$ ), respectively. These results are in excellent agreement with literature ${ }^{143} \mathrm{Nd} /{ }^{144} \mathrm{Nd}$ of $0.512637 \pm 0.000013$ for acid-leached BCR-2 residues ${ }^{88}$ and $0.512791 \pm 0.000013$ for unleached AGV-1 rock powder ${ }^{89}$. Repeat analyses of sample C7 yielded ${ }^{143} \mathrm{Nd} /{ }^{144} \mathrm{Nd}=0.512387 \pm$ 0.000011 ( $2 \mathrm{SD}, n=16)$. All sample Nd isotope results are expressed in epsilon 
notation: $\left.\varepsilon_{\mathrm{Nd}}=\left({ }^{143} \mathrm{Nd} /{ }^{144} \mathrm{Nd}_{\text {sample }}\right) /\left({ }^{143} \mathrm{Nd} /{ }^{144} \mathrm{Nd}_{\mathrm{CHUR}}\right)-1\right] \times 10^{4}$ where CHUR is the Chondritic Uniform Reservoir ${ }^{90}$.

For $\mathrm{Sr}$ isotope analyses, mass bias was corrected for using ${ }^{86} \mathrm{Sr} /{ }^{88} \mathrm{Sr}=0.1194$ and an exponential law. Krypton gas blanks, measured on ${ }^{83} \mathrm{Kr}$ to correct for ${ }^{86} \mathrm{Kr}$ on ${ }^{86} \mathrm{Sr}$, were below $0.1 \mathrm{mV}$, whereas ${ }^{86} \mathrm{Sr}$ was measured at $2-3 \mathrm{~V}$. Isobaric interferences from ${ }^{87} \mathrm{Rb}$ on ${ }^{87} \mathrm{Sr}$ were monitored and corrected using ${ }^{85} \mathrm{Rb}$. Repeat analyses of NIST SRM987 (every four samples) were used to normalize sample ${ }^{87} \mathrm{Sr} /{ }^{86} \mathrm{Sr}$ to SRM987 ${ }^{87} \mathrm{Sr} /{ }^{86} \mathrm{Sr}$ of $0.710248^{91}$. The external reproducibility of acid-leached BCR-2 and AGV-1 was ${ }^{87} \mathrm{Sr} /{ }^{86} \mathrm{Sr}=0.704994 \pm 0.000027(2 \mathrm{SD}, n=32)$ and $0.703950 \pm 0.000025$ ( $2 \mathrm{SD}, n=32)$, respectively. These values are indistinguishable from the values reported previously for acid-leached residues of BCR-2 $(0.705000 \pm 0.000011)^{88}$ and AGV-1 reference materials $(0.703950 \pm 0.000012)^{89}$. Repeat analyses of sample C7 yielded $\mathrm{Sr} /{ }^{86} \mathrm{Sr}=0.710887 \pm 0.000021(2 \mathrm{SD}, n=12)$.

Measurements of the $\mathrm{Pb}$ isotope compositions were performed as standardsample bracketing using NIST SRM981 as bracketing standard ${ }^{92}$. Isobaric interference of ${ }^{204} \mathrm{Hg}$ on ${ }^{204} \mathrm{~Pb}$ was corrected for through monitoring ${ }^{202} \mathrm{Hg}$ $(<0.5 \mathrm{mV})$, whereas ${ }^{204} \mathrm{~Pb}$ was typically measured at $\sim 300-400 \mathrm{mV}$. The instrumental mass bias of sample analyses was corrected for by normalization of the measured SRM981 values to the accepted values of ref. ${ }^{93}$. The external reproducibility was monitored through repeat analyses of secondary reference materials BCR-2 and AGV-1 (literature values in brackets). Selected $\mathrm{Pb}$ isotope results for BCR-2 (2 SD, $n=39)$ were ${ }^{206} \mathrm{~Pb} / 204 \mathrm{~Pb}=18.8030 \pm 0.0025(18.8029 \pm$ $0.0010)^{88},{ }^{207} \mathrm{~Pb} / 204 \mathrm{~Pb}=15.6253 \pm 0.0019(15.6239 \pm 0.0008)^{88}$, and ${ }^{208} \mathrm{~Pb} /{ }^{204} \mathrm{~Pb}=$ $38.8337 \pm 0.0065(38.8287 \pm 0.0025)^{88}$. Repeat analyses of AGV-1 ( $\left.2 \mathrm{SD}, n=39\right)$ yielded ${ }^{206} \mathrm{~Pb} / 204 \mathrm{~Pb}=18.9034 \pm 0.0026(18.9054 \pm 0.0013)^{89},{ }^{207} \mathrm{~Pb} / 204 \mathrm{~Pb}=$ $15.6147 \pm 0.0016(15.6165 \pm 0.0001)^{89}$, and ${ }^{208} \mathrm{~Pb} /{ }^{204} \mathrm{~Pb}=38.5737 \pm 0.0071$ $(38.5875 \pm 0.0220)^{89}$ for the same analytical sessions. Our $\mathrm{Pb}$ isotope results on leached BCR-2 and AGV-1 rock powders demonstrate excellent reproducibility of existing literature values ${ }^{88,89}$ and previous results from the ICBM lab ${ }^{34}$. Repeat analyses of sample $\mathrm{C} 7(n=7)$ yielded ${ }^{206} \mathrm{~Pb} /{ }^{204} \mathrm{~Pb}=19.1504 \pm 0.0017,{ }^{207} \mathrm{~Pb} /$ ${ }^{204} \mathrm{~Pb}=15.6657 \pm 0.0015$, and ${ }^{208} \mathrm{~Pb} / 204 \mathrm{~Pb}=39.1677 \pm 0.0042$. It is noted that our results on acid-leached BCR-2 and AGV-1 rock powders are compared to the acidleached literature results where available, and that the literature $\mathrm{Pb}$ isotope ratios of acid-leached AGV-1 residues are based on only two analyses ${ }^{89}$. The procedural blanks for $\mathrm{Nd}, \mathrm{Pb}$, and $\mathrm{Sr}$ were below $40 \mathrm{pg}, 120 \mathrm{pg}$, and $2.5 \mathrm{ng}$, respectively. Typically, the blank contaminations were significantly less than $1 \%$ of the individual sample $\mathrm{Nd}, \mathrm{Pb}$, and $\mathrm{Sr}$ yields with negligible effects on the respective sample isotope compositions (see also Supplementary Note 6 for more details).

\section{Data availability}

All data presented in this paper are included in this published article and its Supplementary Data files.

Received: 21 January 2020; Accepted: 14 September 2020; Published online: 09 November 2020

\section{References}

1. Lüthi, D. et al. High-resolution carbon dioxide concentration record 650,000-800,000 years before present. Nature 453, 379-382 (2008).

2. Lambert, F. et al. Dust-climate couplings over the past 800,000 years from the EPICA Dome C ice core. Nature 452, 616-619 (2008).

3. Parrenin, F. et al. Synchronous change of atmospheric $\mathrm{CO} 2$ and antarctic temperature during the last deglacial warming. Science 339, 1060-1063 (2013).

4. Sigman, D. M. \& Boyle, E. A. Glacial/interglacial variations in atmospheric carbon dioxide. Nature 407, 859-869 (2000).

5. Martinez-Garcia, A. et al. Southern Ocean dust-climate coupling over the past four million years. Nature 476, 312-315 (2011)

6. Martínez-García, A. et al. Iron fertilization of the subantarctic ocean during the last ice age. Science 343, 1347-1350 (2014).

7. Jaccard, S. L. et al. Two modes of change in Southern Ocean productivity over the past million years. Science 339, 1419-1423 (2013)

8. Martin, J. H. Glacial-interglacial $\mathrm{CO}_{2}$ change: the iron hypothesis Paleoceanography 5, 1-13 (1990).

9. Boyd, P. W. et al. Mesoscale iron enrichment experiments 1993-2005: synthesis and future directions. Science 315, 612-617 (2007).

10. Pollard, R. T. et al. Southern Ocean deep-water carbon export enhanced by natural iron fertilization. Nature 457, 577-580 (2009).

11. Boyd, P. W., Claustre, H., Levy, M., Siegel, D. A. \& Weber, T. Multi-faceted particle pumps drive carbon sequestration in the ocean. Nature 568, 327-335 (2019).

12. Yoon, J.-E. et al. Reviews and syntheses: ocean iron fertilization experiments past, present, and future looking to a future Korean Iron Fertilization Experiment in the Southern Ocean (KIFES) project. Biogeosciences 15, 5847-5889 (2018).
13. Wang, X. T. et al. Deep-sea coral evidence for lower Southern Ocean surface nitrate concentrations during the last ice age. Proc. Natl Acad. Sci. USA 114 3352-3357 (2017).

14. Khatiwala, S., Schmittner, A. \& Muglia, J. Air-sea disequilibrium enhances ocean carbon storage during glacial periods. Sci. Adv. 5, eaaw4981 (2019).

15. Albani, S., Mahowald, N. M., Delmonte, B., Maggi, V. \& Winckler, G. Comparing modeled and observed changes in mineral dust transport and deposition to Antarctica between the Last Glacial Maximum and current climates. Clim. Dyn. 38, 1731-1755 (2012).

16. Neff, P. D. \& Bertler, N. A. N. Trajectory modeling of modern dust transport to the Southern Ocean and Antarctica. J. Geophys. Res. Atmos. 120, 2015JD023304 (2015)

17. Schroth, A. W., Crusius, J., Sholkovitz, E. R. \& Bostick, B. C. Iron solubility driven by speciation in dust sources to the ocean. Nat. Geosci. 2, 337-340 (2009).

18. Shi, Z. et al. Impacts on iron solubility in the mineral dust by processes in the source region and the atmosphere: a review. Aeolian Res. 5, 21-42 (2012).

19. Shoenfelt, E. M. et al. High particulate iron(II) content in glacially sourced dusts enhances productivity of a model diatom. Sci. Adv. 3, e1700314 (2017)

20. Shoenfelt, E. M., Winckler, G., Lamy, F., Anderson, R. F. \& Bostick, B. C. Highly bioavailable dust-borne iron delivered to the Southern Ocean during glacial periods. Proc. Natl Acad. Sci. USA 115, 11180-11185 (2018).

21. Mackie, D. S. et al. Biogeochemistry of iron in Australian dust: from eolian uplift to marine uptake. Geochem. Geophys. Geosyst. 9 (2008).

22. Baker, A. R. \& Croot, P. L. Atmospheric and marine controls on aerosol iron solubility in seawater. Mar. Chem. 120, 4-13 (2010).

23. Albani, S. et al. Paleodust variability since the Last Glacial Maximum and implications for iron inputs to the ocean. Geophys. Res. Lett. 43, 3944-3954 (2016).

24. Winton, V. H. L. et al. The origin of lithogenic sediment in the south-western Ross Sea and implications for iron fertilization. Ant. Sci. 28, 250-260 (2016).

25. Shaked, Y., Buck, K. N., Mellett, T. \& Maldonado, M. T. Insights into the bioavailability of oceanic dissolved $\mathrm{Fe}$ from phytoplankton uptake kinetics. ISME J. 14, 1182-1193 (2020).

26. Prospero, J. M., Ginoux, P., Torres, O., Nicholson, S. E. \& Gill, T. E. Environmental characterization of global sources of atmospheric soil dust identified with the Nimbus 7 total ozone mapping spectrometer (toms) absorbing aerosol product. Rev. Geophys. 40, 2-1-2-31 (2002).

27. Ginoux, P., Prospero, J. M., Gill, T. E., Hsu, N. C. \& Zhao, M. Global-scale attribution of anthropogenic and natural dust sources and their emission rates based on MODIS Deep Blue aerosol products. Rev. Geophys. 50, RG3005 (2012).

28. Gili, S. et al. Glacial/interglacial changes of Southern Hemisphere wind circulation from the geochemistry of South American dust. Earth Planet. Sci. Lett. 469, 98-109 (2017).

29. De Deckker, P. An evaluation of Australia as a major source of dust. Earth Sci. Rev. 194, 536-567 (2019)

30. Smith, J. et al. Isotopic constraints on the source of Argentinian loess - with implications for atmospheric circulation and the provenance of Antarctic dust during recent glacial maxima. Earth Planet. Sci. Lett. 212, 181-196 (2003).

31. Delmonte, B. et al. Comparing the Epica and Vostok dust records during the last 220,000 years: stratigraphical correlation and provenance in glacial periods. Earth Sci. Rev. 66, 63-87 (2004).

32. McGowan, H. A., Kamber, B., McTainsh, G. H. \& Marx, S. K. High resolution provenancing of long travelled dust deposited on the Southern Alps, New Zealand. Geomorphology 69, 208-221 (2005).

33. Gaiero, D. M. Dust provenance in Antarctic ice during glacial periods: from where in southern South America? Geophys. Res. Lett. 34 (2007).

34. Wengler, M. et al. A geochemical approach to reconstruct modern dust fluxes and sources to the South Pacific. Geochim. Cosmochim. Acta 264, 205-223 (2019).

35. De Deckker, P. Airborne dust traffic from Australia in modern and Late Quaternary times. Glob. Planet. Change 184, 103056 (2020).

36. Grousset, F. E. et al. Antarctic (Dome C) ice-core dust at 18 k.y. B.P.: isotopic constraints on origins. Earth Planet. Sci. Lett. 111, 175-182 (1992).

37. Delmonte, B. et al. Aeolian dust in the Talos Dome ice core (East Antarctica, Pacific/Ross Sea sector): Victoria Land versus remote sources over the last two climate cycles. J. Quat. Sci. 25, 1327-1337 (2010).

38. Vallelonga, P. et al. Lead isotopic compositions in the EPICA Dome C ice core and Southern Hemisphere potential source areas. Quat. Sci. Rev. 29, 247-255 (2010).

39. Gili, S. et al. Provenance of dust to Antarctica: a lead isotopic perspective. Geophys. Res. Lett. 43, 2291-2298 (2016).

40. Revel-Rolland, M. et al. Eastern Australia: a possible source of dust in East Antarctica interglacial ice. Earth Planet. Sci. Lett. 249, 1-13 (2006).

41. Lamy, F. et al. Increased dust deposition in the Pacific Southern Ocean during glacial periods. Science 343, 403-407 (2014). 
42. Molina-Kescher, M. et al. Reduced admixture of North Atlantic Deep Water to the deep central South Pacific during the last two glacial periods. Paleoceanography 31, 651-668 (2016).

43. Kok, J. F. et al. Smaller desert dust cooling effect estimated from analysis of dust size and abundance. Nat. Geosci. 10, 274-278 (2017).

44. Delmonte, B. et al. Causes of dust size variability in central East Antarctica (Dome B): atmospheric transport from expanded South American sources during Marine Isotope Stage 2. Quat. Sci. Rev. 168, 55-68 (2017).

45. Wengler, M. Dust variability and provenance in the Pacific and Atlantic sectors of the Southern Ocean. PhD thesis (Bremen, 2018).

46. McCave, I. N., Manighetti, B. \& Robinson, S. G. Sortable silt and fine sediment size/composition slicing: parameters for palaeocurrent speed and palaeoceanography. Paleoceanography 10, 593-610 (1995).

47. Hemming, S. R. et al. Strontium isotope tracing of terrigenous sediment dispersal in the Antarctic Circumpolar Current: implications for constraining frontal positions. Geochem. Geophys. Geosyst. 8, Q06N13 (2007).

48. Aarons, S. M. et al. Dust composition changes from Taylor Glacier (East Antarctica) during the last glacial-interglacial transition: a multi-proxy approach. Quat. Sci. Rev. 162, 60-71 (2017).

49. Holland, P. R. \& Kwok, R. Wind-driven trends in Antarctic sea-ice drift. Nat. Geosci. 5, 872-875 (2012).

50. Simões Pereira, P. et al. Geochemical fingerprints of glacially eroded bedrock from West Antarctica: detrital thermochronology, radiogenic isotope systematics and trace element geochemistry in Late Holocene glacial-marine sediments. Earth Sci. Rev. 182, 204-232 (2018).

51. Basile, I., Petit, J. R., Touron, S., Grousset, F. E. \& Barkov, N. Volcanic layers in Antarctic (Vostok) ice cores: source identification and atmospheric implications. J. Geophys. Res. 106, 31915-31931 (2001).

52. Petherick, L. M., McGowan, H. A. \& Kamber, B. S. Reconstructing transport pathways for late Quaternary dust from eastern Australia using the composition of trace elements of long traveled dusts. Geomorphology 105, 67-79 (2009).

53. Fitzsimmons, K. E. et al. Late Quaternary palaeoenvironmental change in the Australian drylands. Quat. Sci. Rev. 74, 78-96 (2013).

54. De Deckker, P., Norman, M., Goodwin, I. D., Wain, A. \& Gingele, F. X. Lead isotopic evidence for an Australian source of aeolian dust to Antarctica at times over the last 170,000 years. Palaeogeogr. Palaeoclimatol. Palaeoecol. 285, 205-223 (2010).

55. Gingele, F. X. \& Deckker, P. D. Clay mineral, geochemical and Sr-Nd isotopic fingerprinting of sediments in the Murray-Darling fluvial system, southeast Australia. Aust. J. Earth Sci. 52, 965-974 (2005).

56. Feng, J.-L., Zhu, L.-P., Zhen, X.-L. \& Hu, Z.-G. Grain size effect on $\mathrm{Sr}$ and $\mathrm{Nd}$ isotopic compositions in eolian dust: implications for tracing dust provenance and Nd model age. Geochem. J. 43, 123-131 (2009).

57. Garçon, M., Chauvel, C., France-Lanord, C., Limonta, M. \& Garzanti, E. Which minerals control the $\mathrm{Nd}-\mathrm{Hf}-\mathrm{Sr}-\mathrm{Pb}$ isotopic compositions of river sediments? Chem. Geol. 364, 42-55 (2014).

58. Lucassen, F. et al. Composition and density model of the continental crust at an active continental margin-the Central Andes between $21^{\circ}$ and $27^{\circ} \mathrm{S}$. Tectonophysics 341, 195-223 (2001).

59. Bock, B., Bahlburg, H., Wörner, G. \& Zimmermann, U. Tracing crustal evolution in the southern Central Andes from Late Precambrian to Permian with geochemical and $\mathrm{Nd}$ and $\mathrm{Pb}$ isotope data. J. Geol. 108, 515-535 (2000).

60. Gaiero, D. M. et al. Ground/satellite observations and atmospheric modeling of dust storms originating in the high Puna-Altiplano deserts (South America): implications for the interpretation of paleo-climatic archives. $J$. Geophys. Res. Atmos. 118, 3817-3831 (2013).

61. Perlwitz, J. P., Pérez García-Pando, C. \& Miller, R. L. Predicting the mineral composition of dust aerosols - Part 1: representing key processes. Atmos. Chem. Phys. 15, 11593-11627 (2015)

62. Gaudichet, A. et al. Mineralogy of insoluble particles in the Vostok Antarctic ice core over the last climatic cycle (150 kyr). Geophys. Res. Lett. 15, 1471-1474 (1988).

63. Gaiero, D. M., Depetris, P. J., Probst, J.-L., Bidart, S. M. \& Leleyter, L. The signature of river- and wind-borne materials exported from Patagonia to the southern latitudes: a view from REEs and implications for paleoclimatic interpretations. Earth Planet. Sci. Lett. 219, 357-376 (2004)

64. Gingele, F. X., De Deckker, P. \& Hillenbrand, C.-D. Late Quaternary terrigenous sediments from the Murray Canyons area, offshore South Australia and their implications for sea level change, palaeoclimate and palaeodrainage of the Murray-Darling Basin. Mar. Geol. 212, 183-197 (2004).

65. Marx, S. K., Kamber, B. S. \& McGowan, H. A. Provenance of long-travelled dust determined with ultra-trace-element composition: a pilot study with samples from New Zealand glaciers. Earth Surf. Process. Landf. 30, 699-716 (2005).

66. Marx, S. K., McGowan, H. A. \& Kamber, B. S. Long-range dust transport from eastern Australia: a proxy for Holocene aridity and ENSO-type climate variability. Earth Planet. Sci. Lett. 282, 167-177 (2009).
67. Cosentino, N. J. et al. Atmospheric dust dynamics in southern South America: a 14-year modern dust record in the loessic Pampean region. Holocene 30 575-588 (2020)

68. Lamy, F. et al. Precession modulation of the South Pacific westerly wind belt over the past million years. Proc. Natl Acad. Sci. USA 116, 23455-23460 (2019).

69. Ammann, C., Jenny, B., Kammer, K. \& Messerli, B. Late Quaternary glacier response to humidity changes in the arid Andes of Chile (18-29 $\mathrm{S})$. Palaeogeogr. Palaeoclimatol. Palaeoecol. 172, 313-326 (2001).

70. Zech, J., Terrizzano, C., García-Morabito, E., Veit, H. \& Zech, R. Timing and extent of late pleistocene glaciation in the arid Central Andes of Argentina and Chile $\left(22^{\circ}-41^{\circ} \mathrm{S}\right)$. Cuad. Investig. Geogr. 43, 697-718 (2017).

71. Pichat, S., Abouchami, W. \& Galer, S. J. G. Lead isotopes in the Eastern Equatorial Pacific record Quaternary migration of the South Westerlies. Earth Planet. Sci. Lett. 388, 293-305 (2014)

72. Chiang, J. C. H., Lee, S.-Y., Putnam, A. E. \& Wang, X. South Pacific Split Jet, ITCZ shifts, and atmospheric North-South linkages during abrupt climate changes of the last glacial period. Earth Planet. Sci. Lett. 406, 233-246 (2014).

73. Bals-Elsholz, T. M. et al. The Wintertime Southern Hemisphere Split Jet: structure, variability, and evolution. J. Clim. 14, 4191-4215 (2001).

74. Garreaud, R., Lopez, P., Minvielle, M. \& Rojas, M. Large-scale control on the Patagonian climate. J. Clim. 26, 215-230 (2013).

75. Milana, J. P. \& Kröhling, D. M. First data on volume and type of deflated sediment from Southern Puna Plateau and its role as source of the ChacoPampean loess. Quat. Int. 438, 126-140 (2017).

76. McGee, D. et al. Tracking eolian dust with helium and thorium: impacts of grain size and provenance. Geochim. Cosmochim. Acta 175, 47-67 (2016).

77. Benz, V., Esper, O., Gersonde, R., Lamy, F. \& Tiedemann, R. Last Glacial Maximum sea surface temperature and sea-ice extent in the Pacific sector of the Southern Ocean. Quat. Sci. Rev. 146, 216-237 (2016)

78. Honjo, S., Francois, R., Manganini, S., Dymond, J. \& Collier, R. Particle fluxes to the interior of the Southern Ocean in the Western Pacific sector along $170^{\circ}$ W. Deep Sea Res. Part II Top. Stud. Oceanogr. 47, 3521-3548 (2000).

79. Trull, T. W., Bray, S. G., Manganini, S. J., Honjo, S. \& François, R. Moored sediment trap measurements of carbon export in the Subantarctic and Polar Frontal zones of the Southern Ocean, south of Australia. J. Geophys. Res. 106, 31489-31509 (2001).

80. McCave, I. N. Size spectra and aggregation of suspended particles in the deep ocean. Deep Sea Res. Part A Oceanogr. Res. Pap. 31, 329-352 (1984).

81. Klaas, C. \& Archer, D. E. Association of sinking organic matter with various types of mineral ballast in the deep sea: Implications for the rain ratio. Glob. Biogeochem. Cycles 16, 63-1 (2002).

82. Vázquez, M. et al. Regolith production and chemical weathering of granitic rocks in central Chile. Chem. Geol. 446, 87-98 (2016).

83. Lugmair, G. W. \& Galer, S. J. G. Age and isotopic relationships among the angrites Lewis Cliff 86010 and Angra dos Reis. Geochim. Cosmochim. Acta 56, 1673-1694 (1992).

84. Cohen, A. S., O'Nions, R. K., Siegenthaler, R. \& Griffin, W. L. Chronology of the pressure-temperature history recorded by a granulite terrain. Contr. Mineral. Pet. 98, 303-311 (1988).

85. Horwitz, E. P., Chiarizia, R. \& Dietz, M. L. A novel strontium-selective extraction chromatographic resin. Solvent Extr. Ion. Exch. 10, 313-336 (1992).

86. Pin, C. \& Zalduegui, J. S. Sequential separation of light rare-earth elements, thorium and uranium by miniaturized extraction chromatography: application to isotopic analyses of silicate rocks. Anal. Chim. Acta 339, 79-89 (1997).

87. Tanaka, T. et al. JNdi-1: a neodymium isotopic reference in consistency with LaJolla neodymium. Chem. Geol. 168, 279-281 (2000).

88. Jweda, J., Bolge, L., Class, C. \& Goldstein, S. L. High precision Sr-Nd-Hf-Pb isotopic compositions of USGS reference material BCR-2. Geostand. Geoanal. Res. 40, 101-115 (2016).

89. Weis, D. et al. High-precision isotopic characterization of USGS reference materials by TIMS and MC-ICP-MS. Geochem. Geophys. Geosyst. 7, Q08006 (2006).

90. Jacobsen, S. B. \& Wasserburg, G. J. Sm-Nd isotopic evolution of chondrites. Earth Planet. Sci. Lett. 50, 139-155 (1980).

91. Thirlwall, M. F. Long-term reproducibility of multicollector $\mathrm{Sr}$ and Nd isotope ratio analysis. Chem. Geol. 94, 85-104 (1991).

92. Albarède, F. et al. Precise and accurate isotopic measurements using multiplecollector ICPMS. Geochim. Cosmochim. Acta 68, 2725-2744 (2004).

93. Galer, S. J. G. \& Abouchami, W. Practical application of lead triple spiking for correction of instrumental mass discrimination. Mineral. Mag. 62A, 491-492 (1998). 
94. Orsi, A. H., Whitworth III, T. \& Nowlin, W. D.Jr. On the meridional extent and fronts of the Antarctic Circumpolar Current. Deep Sea Res. Pt. I Oceanogr. Res. Pap. 42, 641-673 (1995).

95. Schlitzer, R. Ocean Data View odv.awi.de (2019).

96. Lang Farmer, G., Licht, K., Swope, R. J. \& Andrews, J. Isotopic constraints on the provenance of fine-grained sediment in LGM tills from the Ross Embayment, Antarctica. Earth Planet. Sci. Lett. 249, 90-107 (2006).

97. Hart, S. R. A large-scale isotope anomaly in the Southern Hemisphere mantle. Nature 309, 753-757 (1984).

\section{Acknowledgements}

We acknowledge the crews and science teams of cruises E17, SO213, PS35, PS58, PS75, and PS97 for collecting sample material, which was in part supported by NSF grant OCE09-35115 to K.P. We thank B.G. Koffman and S.L. Goldstein for valuable discussions on dust provenance, as well as M. Schulz and S. Wiebe for support during sample preparation. We acknowledge financial support from the Max Planck Society and the Helmholtz Association. Open Access funding enabled by the DFG open access publication fund and the Carl von Ossietzky University Oldenburg.

\section{Author contributions}

T.S., K.P., F.L., and G.W. designed the research and led the draft of this manuscript. P.B. supported T.S. during the geochemical analyses. F.L. and M.W. provided sample material and helped during sample preparation. All authors contributed to the data interpretation.

\section{Competing interests}

The authors declare no competing interests.

\section{Additional information}

Supplementary information is available for this paper at https://doi.org/10.1038/s41467020-18858-y.

Correspondence and requests for materials should be addressed to T.S.

Peer review information Nature Communications thanks the anonymous reviewers for their contributions to the peer review of this work.

Reprints and permission information is available at http://www.nature.com/reprints

Publisher's note Springer Nature remains neutral with regard to jurisdictional claims in published maps and institutional affiliations.

(c) (i) Open Access This article is licensed under a Creative Commons Attribution 4.0 International License, which permits use, sharing, adaptation, distribution and reproduction in any medium or format, as long as you give appropriate credit to the original author(s) and the source, provide a link to the Creative Commons license, and indicate if changes were made. The images or other third party material in this article are included in the article's Creative Commons license, unless indicated otherwise in a credit line to the material. If material is not included in the article's Creative Commons license and your intended use is not permitted by statutory regulation or exceeds the permitted use, you will need to obtain permission directly from the copyright holder. To view a copy of this license, visit http://creativecommons.org/ licenses/by/4.0/.

(c) The Author(s) 2020 